\title{
A INSERÇÃO DO MIGRANTE HAITIANO NO MUNDO DO TRABALHO NO MUNICÍPIO DE CASCAVEL/PR
}

\author{
Lineker Alan Gabriel Nunes \\ Instituto Federal de Educação, Ciência e Tecnologia do Paraná, Cascavel, PR, Brasil \\ lineker.nunes@ifpr.edu.br \\ Ideni Terezinha Antonello \\ Universidade Estadual de Londrina, Departamento de Geografia, Londrina, PR, Brasil \\ antonello@uel.br
}

\begin{abstract}
RESUMO
O presente artigo tem como escopo apresentar os resultados da pesquisa acerca da migração e do trabalho dos imigrantes haitianos no município de Cascavel/PR. O objetivo é analisar a inserção do migrante haitiano no mundo do trabalho no município de Cascavel/PR. Para tanto, buscou-se abordar a migração dos haitianos para o Brasil e analisar a inserção do migrante haitiano no mundo do trabalho no município. A metodologia foi composta de levantamento bibliográfico de obras que tratam do trabalho, como também pesquisa de campo com aplicação de entrevistas e questionários com os diversos sujeitos envolvidos na migração haitiana em Cascavel/PR. A partir da discussão, têm-se como resultados: A espacialização da migração haitiana intra-urbana no município, por meio da geração de produto cartográfico; Conhecimento das motivações que levaram à migração e conhecimento das dificuldades e preconceitos sofridos pelos migrantes no ambiente de trabalho; Levantamento do perfil sócio-econômico dos migrantes haitianos em Cascavel. Conclui-se que a migração haitiana no município está intimamente ligada ao trabalho (e à precarização do trabalho) no setor frigorífico e na construção civil, constatando-se que os limites impostos pelo capital no trabalho, são também os limites impostos à migração haitiana.
\end{abstract}

Palavras-chave: Migração. Haitianos. Trabalho. Cascavel/PR.

\section{THE INSERTION OF THE HAITIAN MIGRANT INTO THE WORLD OF WORK OF CASCAVEL/PR}

\begin{abstract}
This article aims to present the results of the research on migration and the work of Haitian immigrants in the Cascavel / PR municipality. The objective is to analyze the insertion of Haitian migrants in the world of work in the Cascavel / PR municipality. To this end, we sought to address the migration of Haitians to Brazil and to analyze the insertion of Haitian migrants in the world of work in the municipality. The methodology consisted of a bibliographic research in documents that address the topic of work, as well as field research with the application of interviews and questionnaires with the various subjects involved in Haitian migration in Cascavel / PR. From the discussion, these are the results: The geographical space of intra-urban Haitian migration in the municipality, through the generation of cartographic product; Knowledge of the motivations that led to migration and knowledge of the difficulties and prejudices suffered by migrants in the work environment; and Survey of the socio-economic profile of Haitian migrants in Cascavel. It is concluded that Haitian migration in the municipality is closely linked to work (and precarious work) in the slaughterhouse and civil construction sectors, noting that the limits imposed by capital at work are also the limits imposed on Haitian migration.
\end{abstract}

Keywords: Migration. Haitians. Job. Cascavel / PR.

\section{INTRODUÇÃO}

O presente artigo tem como intuito apresentar os resultados da investigação realizada sobre o fenômeno da migração haitiana em direção ao Brasil, tendo como recorte espacial da pesquisa o município de Cascavel/PR.

$\begin{array}{lllll}\text { Caminhos de Geografia } \quad \text { Uberlândia-MG } & \text { v. } 21, \text { n. } 78 & \text { Dez/2020 } & \text { p. } 65-77 & \text { Página } 65\end{array}$


Pensando-se na migração haitiana em direção a outros países, comumente considera-se que as diásporas (grandes movimentos de saída da população) haitianas são responsáveis pelos grandes fluxos emigratórios do país. Deve-se atentar à instabilidade política e econômica e às condições sócio estruturais, fatores esses - dentre outros - predominantes para a migração de haitianos em direção aos Estados Unidos (a partir dos anos 1970), França, Canadá e mais recentemente ao Brasil, a partir de 2011 (BAPTISTE e VIEIRA, 2016).

Nesse sentido, a premissa principal da pesquisa assenta-se no trabalho como sendo concebido na prática como a busca por emprego e melhores condições de vida, como o grande impulsionador da migração haitiana em direção ao Brasil.

Outro ponto que deve ser considerado é a histórica tradição de emigração da população haitiana. Aproximadamente $1 / 3$ da população haitiana vive no exterior, sendo um total de aproximadamente 4,5 milhões de pessoas. Salienta-se a importância desse fluxo para as famílias dos migrantes mediante as remessas enviadas aos que estão no país. A dependência financeira do país em relação às remessas é tamanha que as mesmas constituem-se como o décimo primeiro departamento administrativo do país (BAPTISTE e VIEIRA, 2016, p. 590).

A migração haitiana no Brasil inicia-se por volta de 2011, com um grande fluxo de imigrantes adentrando no território brasileiro via fronteira norte do país, mais especificamente pelos estados do Acre e do Amazonas, nos municípios de Assis Brasil, Brasiléia e Tabatinga. Posteriormente, por conta da intervenção estatal e da criação da resolução ํำ $97 / 2012^{1}$, há a criação do visto humanitário, destinado a nacionais do Haiti. A partir daí, há uma redução da migração haitiana via fronteira norte do Brasil e um posterior aumento principalmente por via aérea (FERNANDES e FARIA, 2016).

Mas, quais são os motivos para o desencadeamento da migração haitiana em direção ao Brasil? Correntemente associa-se o fluxo migratório de haitianos para o Brasil unicamente ao terremoto de janeiro 2010. Baptiste e Vieira (2016) informam que são vários os fatores que incentivaram a migração ao Brasil, podendo-se citar: a crise financeira internacional de 2008; o endurecimento da legislação migratória nos países desenvolvidos, aumentando as restrições à migração internacional; a presença do Brasil no Haiti, sendo líder da Missão das Nações Unidas para a Estabilização do Haiti (Minustah); a imagem do Brasil no exterior, como sendo um país com economia próspera; a porosidade das fronteiras do norte do Brasil.

Assim, a partir dos anos 2010, observa-se um endurecimento da política migratória dos países europeus e dos Estados Unidos, destinos já tradicionais dentro da rota das migrações haitianas. Logo, o Brasil passa a fazer parte uma nova tendência migratória, em que contingentes populacionais de países periféricos tendem a migrar para países emergentes ou num maior patamar econômico (mas também periféricos), considerando-se a divisão internacional do trabalho. Villen (2015), tratando das percepções acerca de supostas ameaças de imigrantes à disponibilidade de emprego no Brasil, chama essa dinâmica de periféricos na periferia. Assim, o termo se refere:

[...] a particularidade da força de trabalho de imigrantes e refugiados provenientes de países periféricos que, por meio dos deslocamentos internacionais, se encontram novamente vivendo e trabalhando num país periférico: daí a denominação periféricos na periferia (VILLEN, 2015, p. 250, grifo do autor).

Mas qual é a relação de Cascavel/PR com esse fluxo? Ocorre que, de maneira geral, a estrutura do mercado de trabalho do município de Cascavel conta com empresas representativas do ramo agroindustrial (Coopavel, Globoaves, dentre outras) e com empresas do ramo da construção civil. A partir de 2012 há no município uma grande demanda de força de trabalho, que na época, não era suprida pela força de trabalho local. Com isso, as empresas lançam como estratégia, para suprir a demanda, a inserção da força de trabalho dos imigrantes haitianos.

Segundo dados da Polícia Federal em Cascavel, em 2017, foi realizado no município o Registro Nacional Migratório de uma população de 2.023 haitianos, sendo importante esclarecer que os dados da Polícia Federal não estimam a população residente total. Ocorre que, sendo um fluxo migratório novo e rápido, há uma série de desdobramentos/consequências, a saber: o racismo e a xenobia por parte da população local; dificuldade para conseguir inserir-se no mercado de trabalho; ausência de políticas públicas que tenham efetividade e contribuam para a inserção no mercado de trabalho; condições sócio-estruturais de moradia precárias, dentre outras.

${ }^{1}$ A resolução normativa $n^{\circ}$ 97/2012 dispunha sobre a concessão de visto permanente a nacionais do Haiti, por razões humanitárias. 
O procedimento metodológico da pesquisa se alicerçou no levantamento bibliográfico para a elaboração de um arcabouço teórico e metodológico fundamental para análise da categoria trabalho e para a investigação acerca da migração haitiana em direção ao Brasil. Bem como desenvolveu-se uma pesquisa empírica mediante a realização de vários trabalhos de campo. Nesse sentido, cita-se as entrevistas realizadas com um agente da Polícia Federal responsável pelo setor de migração, assim como com a representante da Cáritas Cascavel, que atua na acolhida e assistência social aos imigrantes e principalmente com os imigrantes haitianos residentes em Cascavel.

Assim, o presente artigo encontra-se estruturado em dois eixos centrais. No primeiro item, apresentamos uma discussão acerca da categoria trabalho e suas implicações perante o sistema de mediações do capital. Também é realizada discussão acerca da mobilidade da força de trabalho e sua relação com os imigrantes haitianos em Cascavel.

Já no segundo item, desenvolve-se uma análise dos resultados da pesquisa, advindos de investigação empírica com os imigrantes haitianos em Cascavel e órgãos que trabalham na acolhida e auxílio aos imigrantes no município.

\section{A CATEGORIA TRABALHO}

Considerando-se a centralidade da categoria trabalho, sabe-se que o mesmo configura-se como a categoria ontológica fundamental para a (re) produção da vida humana (THOMAZ JUNIOR, 2004). É aquilo que nos diferencia dos animais, por exemplo, sendo responsável por um conjunto de transformações no espaço geográfico (MARX, 1996).

Nesse sentido, Marx (1996) considera que o trabalho difere os seres humanos dos animais, tendo como premissa que o homem, antes de concretizar as suas ações (trabalho) para uma finalidade, idealiza o produto final do trabalho na sua mente. Em passagem clássica, Marx diferencia o pior arquiteto da melhor abelha, ao afirmar que o pior arquiteto:

[...] construiu o favo em sua cabeça, antes de construí-lo em cera. No fim do processo de trabalho obtém-se um resultado que já no início deste existiu na imaginação do trabalhador, e portanto idealmente. Ele não apenas efetua uma transformação da forma da matéria natural; realiza, ao mesmo tempo, na matéria natural seu objetivo, que ele sabe que determina, como lei, a espécie e o modo de sua atividade e ao qual tem de subordinar sua vontade (MARX, 1996, p. 298).

Ao se pensar no contexto capitalista e no que tange a relação do capital com os sujeitos envolvidos, Marx (1996) trata do chamado exército industrial de reserva, que se constitui a partir do interesse da classe capitalista em manter uma classe trabalhadora excedente, forçando a uma tendência na baixa nos salários e criando assim uma grande ou até ilimitada força de trabalho ociosa e excedente. De acordo com o autor,

[...] se uma população trabalhadora excedente é produto necessário da acumulação ou do desenvolvimento da riqueza com base no capitalismo, essa superpopulação torna-se, por sua vez, a alavanca da acumulação capitalista, até uma condição de existência do modo de produção capitalista. Ela constitui um exército industrial de reserva disponível, que pertence ao capital de maneira tão absoluta, como se ele o tivesse criado à sua própria custa. Ela proporciona às suas mutáveis necessidades de valorização o material humano sempre pronto para ser explorado, independente dos limites do verdadeiro acréscimo populacional (MARX, 1996, p. 263).

Ao se colocar isso dentro da questão migratória, constata-se que a força de trabalho estrangeira (como exército industrial de reserva), sendo qualificada ou não, é proveitosa para o capitalista, pois gera força de trabalho excedente, diminuindo a autonomia do trabalhador e contribuindo para a precarização do trabalho.

A questão colocada remete aos imigrantes haitianos no mercado de trabalho brasileiro e em Cascavel/PR. Sendo contratados na maioria das vezes por empresas do ramo frigorífico e da construção civil, os mesmos (assim como todos os trabalhadores) encontram-se sujeitos às dinâmicas do mercado desses segmentos. Vê-se aí claramente a não-existência de fronteiras para a ação do capital, haja vista a migração de haitianos para o Brasil. Tratando-se de um trabalhador que é desprovido de bens e capital, há uma facilidade no que tange sua mudança.

Já no que se refere ao migrante ou à força de trabalho exercida por ele, Gaudemar (1977) trata da mobilidade da força de trabalho e suas implicações num contexto capitalista. O autor coloca que a

$\begin{array}{lllll}\text { Caminhos de Geografia } \quad \text { Uberlândia-MG } & \text { v. 21, n. } 78 \quad \text { Dez/2020 } & \text { p. 65-77 } & \text { Página } 67\end{array}$


mobilidade da força de trabalho é uma característica do trabalhador "[...] submetido ao capital e por essa razão do modo de produção capitalista. Ela funda a condição de exercício da força de trabalho como mercadoria, distinguindo assim definitivamente o trabalhador livre do escravo [...]" (GAUDEMAR, 1977, p. 192).

Assim, considerando-se que a mobilidade da força de trabalho é, antes de tudo, condicionada à mobilidade do capital, atribui-se ao trabalhador "liberdade" para, de acordo com seus anseios e vontades, escolher onde trabalhar. A liberdade de escolher o local de trabalho e onde exercê-lo, sabe-se, não se apresenta na realidade como tal, mas aliena o trabalhador a uma gama muito limitada de atividades e locais de trabalho. Observa-se que o limite da mobilidade da força de trabalho é o limite colocado pelo capital para a expansão do trabalho. Há que se ressaltar o fato de que a força de trabalho deve ser móvel, estando apta a deslocar-se.

Ao se referir ao sujeito dos processos migratórios (não somente à migração), que se encontra propenso à mobilidade do capital e do trabalho, Sayad (1998) nos traz elementos de fundamental importância para a compreensão do sujeito que migra. Sayad (1998), tratando da migração de Argelinos para a França, traz uma importante indagação à tona: O que é um imigrante? Indo muito além das concepções clássicas que tratam o imigrante como alguém que "chega", Sayad coloca que o imigrante é uma força de trabalho, geralmente temporária e em trânsito. A finalidade de ser imigrante carrega consigo o objetivo de ser um trabalhador. Conforme Sayad (1998, p. 54-55):

Afinal, o que é um imigrante? Um imigrante é essencialmente uma força de trabalho, e uma força de trabalho provisória, temporária, em trânsito. Em virtude desse princípio, um trabalhador imigrante (sendo que trabalhador e imigrante são, neste caso, quase um pleonasmo), mesmo se nasce para a vida (e para a imigração) na imigração, mesmo se é chamado a trabalhar (como imigrante) durante toda a sua vida no país, mesmo se está destinado a morrer (na imigração), como imigrante, continua sendo um trabalhador definido e tratado como provisório, ou seja, revogável a qualquer momento. A estadia autorizada ao imigrante está inteiramente sujeita ao trabalho, única razão que lhe é reconhecida [...].

Para Sayad, "a razão de ser migrante" está no trabalho. Trabalho este que caracterizará o imigrante dentro dos espaços ao qual este estará inserido. Questiona-se o por que ou os motivos que levam as populações à migração. Sayad (1998, p. 57) elucida que:

[...] só se aceita emigrar e, como uma coisa leva à outra, só se aceita viver em terra estrangeira num país estrangeiro (i. e.. imigrar), com a condição de se convencer de que isso não passa de uma provação, passageira por definição, uma provação que comporta em si mesma sua própria resolução.

O imigrante, por mais que o faça espontaneamente, busca a melhoria das condições de vida em outro local e, ora ou outra, almeja o retorno à sua terra de origem, por mais que não o consiga. Sem buscar entrar em análises subjetivas, concordamos com Sayad (1998) quando colocado que o migrante vê o ato migratório como algo passageiro, provisório e passível de resolução futura.

O imigrante haitiano, sendo um sujeito que, muitas vezes dispõe apenas de sua força de trabalho, encontra-se subordinado à dinâmica do capital colocada por Marx (1996), Gaudemar (1977) e Sayad (1998). Considera-se que o trabalho é elemento central para o migrante, podendo ser o vetor de sua entrada nas dinâmicas internas do país ao qual está se inserindo, como também motivo de frustração, desrealização enquanto quem trabalha, por conta das barreiras e dificuldades em relação ao trabalho, enfrentada pelos migrantes.

\section{MIGRAÇÃO E TRABALHO DOS HAITIANOS EM CASCAVEL/PR}

No que tange os resultados da pesquisa (advindos de investigação bibliográfica e empírica) referentes ao recorte espacial do município de Cascavel, contata-se a migração com vistas ao ato laborativo. Assim, discorrer-se-á no sentido de caracterizar a migração e evidenciar o trabalho como elemento central da presença dos imigrantes no município. Do mesmo modo, busca-se abordar problemas/obstáculos enfrentados pelos imigrantes, tais como: xenofobia, validação de diplomas nas instituições, dificuldades em relação às moradias, entre outros.

Para tanto, a metodologia foi composta de entrevistas e dados dos migrantes cedidos pela Cáritas Arquidiocesana de Cascavel. O objetivo principal foi buscar abarcar ao máximo os sujeitos envolvidos no proccesso migratório. Ao todo, foram realizadas 12 entrevistas (gravadas e transcritas), entre 
janeiro e setembro de 2017, distribuidas da seguinte forma: 7 - imigrantes haitianos, 1 - entrevista coletiva com grupo de haitianos, 1 - responsável pelo setor de migração da Polícia Federal em Cascavel, 1 - representante da Cáritas Cascavel, 1- pastor que atua na acolhida dos imigrantes no município, 1 - vereador responsável pela lei do dia do imigrante haitiano no município de Cascavel.

Sabe-se que o município de Cascavel passa a ser rota da imigração haitiana no Brasil a partir de 2012. As informações, além de contar com registro em órgãos oficiais, também estão presentes em jornais de circulação local e regional. Em 2012, há registros da chegada de 44 haitianos - sendo 41 homens e 3 mulheres - em Cascavel. Os imigrantes foram contratados para a construção de um hospital e de um novo bloco de uma faculdade particular do município. Observa-se que:

O grupo estava refugiado na cidade de Brasiléia, na fronteira do Acre com a Bolívia, desde o início de dezembro. Após chegar ilegalmente ao país em busca de emprego, os imigrantes foram procurados para trabalhar de forma legal. Na capital do Acre, Rio Branco, todos tiveram a documentação regularizada e receberam CPF, Carteira de Trabalho e passaporte. (JORNAL HOJE, 31/01/2012)

O discurso empregado pelos veículos de comunicação, em relação à presença haitiana no município de Cascavel, vai de encontro com a questão da carência de força de trabalho nas principais atividades produtivas do município: agroindústria (por meio dos frigoríficos) e construção civil. Como exemplo, tem-se:

[...] Há seis meses nós procuramos mão de obra e não conseguimos suprir toda a necessidade. Mas o que pesou muito também foi a questão social, explica o engenheiro responsável pelas obras, Carlos Oya. O contato com os estrangeiros foi intermediado pela Secretaria de Justiça e Segurança Pública do Acre. O estado é a principal porta de entrada dos haitianos no Brasil. (GAZETA DO POVO, 30/01/2012)

Desde então, estima-se que a presença haitiana em Cascavel se deve à possibilidade de sua inserção no mercado de trabalho. Os imigrantes que se dirigiram ao município posteriormente, o fizeram em virtude da contratação na fronteira do Acre e/ou por meio de informações com outros imigrantes por intermédio das redes sociais.

Os desligamentos a pedido do próprio trabalhador na época costumavam ser frequentes, apontando para um movimento de rejeição ao trabalho em frigoríficos por parte da classe trabalhadora local. Por exemplo, no ano de 2011, nas profissões de Abatedor e Retalhador de Carne (intimamente ligadas aos frigoríficos), o número total de admissões foi de 163 e 104, enquanto que os desligamentos a pedido do próprio trabalhador são de 115 e 107, respectivamente (CAGED, 2011). Então, a força de trabalho haitiana surge na época (a partir de 2012), como alternativa para a questão da carência de força de trabalho nas atividades produtivas em ascensão no município. Desse modo,

[...] a migração haitiana veio a calhar para os empresários do setor. No princípio os haitianos foram buscados no Acre, por onde a maioria deles ingressou no Brasil. Posteriormente, tendo se estabelecido no município de Cascavel, os próprios haitianos passaram a chamar amigos e parentes em razão da oferta de emprego nos frigoríficos. (MARTINS et al, 2014, p. 6)

Há, com isso, uma consolidação do fenômeno migratório haitiano no município de Cascavel, havendo, cotidianamente, ano a ano, a partir de 2012, uma maior presença dos imigrantes nos diferentes espaços do município. Considerando-se o mercado trabalho como motivador desse fenômeno:

Não é exagero afirmar que eles fazem parte de um exército mundial de trabalhadores da indústria da alimentação, e que Cascavel se converteu no elo de uma cadeia produtiva global, cujo produto é exportado para mais de 150 países. (MARTINS et al, 2014, p. 6)

Dessa forma, há a consolidação do fluxo migratório de haitianos para Cascavel. Assim, em 2012 viviam em Cascavel 97 haitianos, já em 2013, o número salta para 279 e em 2014, para 599 imigrantes (SINCRE, 2014). Em 2016, o município contava com uma população de 2.023 haitianos. Comparando-se a população haitiana residente em Cascavel/PR a outros municípios do Oeste do Paraná, tais como Palotina (257), Cafelândia (207) e Toledo (140), o município concentra o maior número de imigrantes. Ressalta-se, no caso dos últimos dados, que os registros da Polícia Federal não estimam a população residente, mas sim indicam o município de residência na data da produção do registro. 
O primeiro elemento que se percebe na dinâmica socioespacial do migrante em Cascavel é que sua distribuição/localização das residências (figura 1) ocorre nas proximidades dos terminais urbanos, já que sua localização tende a facilitar a mobilidade no município. Observa-se a concentração de imigrantes nas proximidades de locais que atuam na acolhida e na inserção dos imigrantes nos diferentes espaços do município e nas proximidades de empresas que, desde a chegada dos imigrantes, tendem a empregá-los.

Figura 1 - Distribuição territorial dos imigrantes haitianos no município de Cascavel/PR.

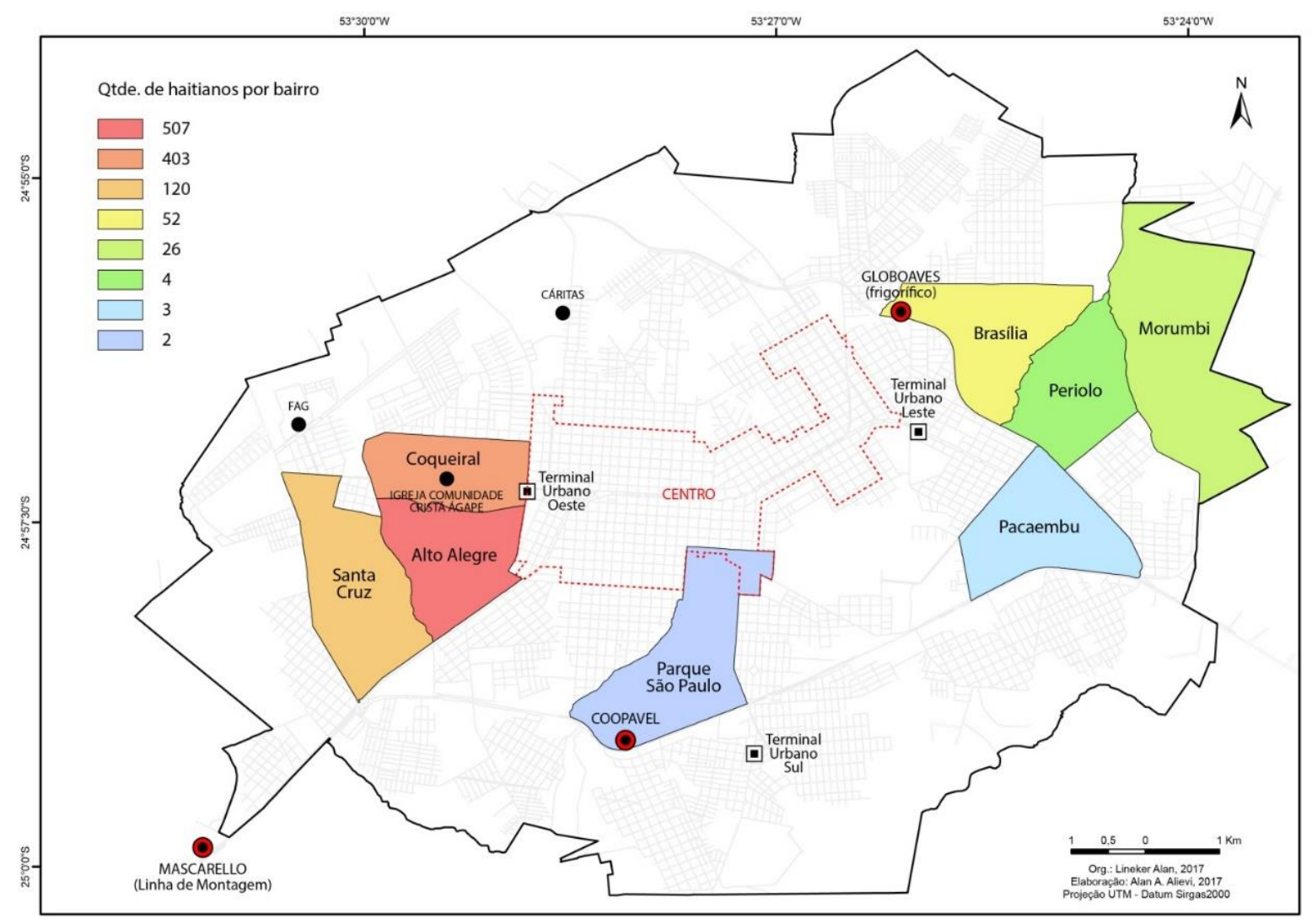

Fonte - Elaboração de Alievi (2017) e organização de Nunes (2017).

O conhecimento da distribuição especial dos imigrantes haitianos no espaço intra-urbano de Cascavel se deu a partir de pesquisas de campo, com informações da Cáritas arquidiocesana de Cascavel e de outras instituições que atuam na assistência e acolhida do imigrante. Além disso, a visita aos frigoríficos e terminais de ônibus, a partir da observação empírica, no cotidiano, permitiu um olhar mais abrangente sobre a espacialização dos imigrantes haitianos.

Assim, em relação ao trabalho dos imigrantes haitianos em Cascavel o gráfico 1, com base nos dados da Cáritas Cascavel, nos anos de 2015, 2016 e 2017, mostra que, além do emprego dos imigrantes nas empresas/atividades tradicionais, há também a questão do desemprego sendo latente. Ressalta-se que os dados da Cáritas não referem-se à totalidade dos migrantes haitianos no munícipio, pois logicamente, boa parte dos mesmos, quando necessitam de ajuda, recorrem ou são atendidos por outras instituições de mesmo cunho. 
Gráfico 1 - Ocupação dos imigrantes haitianos em Cascavel - 2015, 2016 e $2017^{2}$.

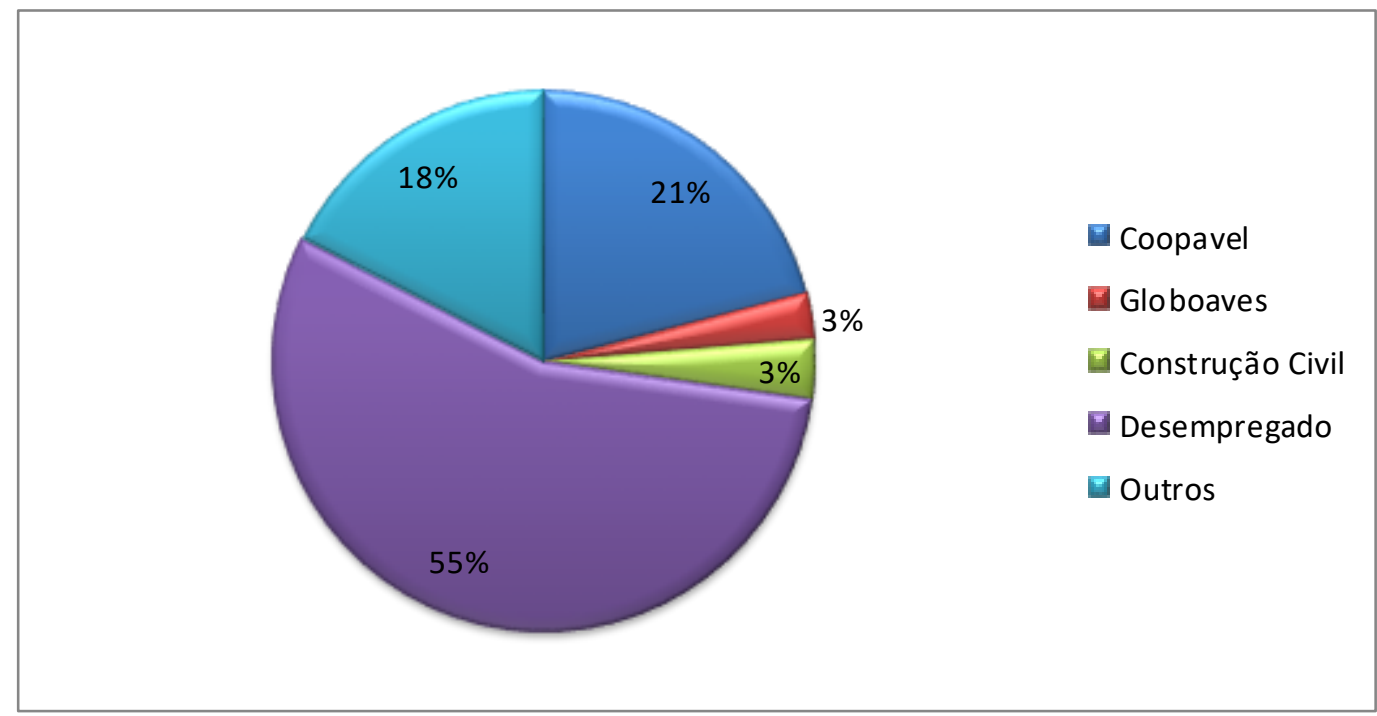

Fonte - Cáritas Arquidiocesana de Cascavel (2017).

Organizador - O próprio autor.

Assim, o número total da amostra do gráfico 1 é de 257 pessoas. Nota-se que a grande maioria $(55 \%$ ou 142 pessoas), encontravam-se desempregadas, enquanto que $21 \%$ trabalhavam na Coopavel, $4 \%$ na construção civil, $3 \%$ na Globoaves e 18\% em outras atividades (Restaurantes, hotéis, Postos de combustíveis, madeireiras, dentre outros).

Deve-se atentar ao grande número de imigrantes haitianos que se encontravam ou encontram-se desempregados no município. Observa-se uma menor absorção da força de trabalho imigrante nas atividades produtivas tradicionais, mostrando uma mudança no cenário e no mundo do trabalho para o imigrante haitiano.

Pode-se verificar uma homogeneidade em relação à inserção dos imigrantes no mercado de trabalho. Ao se considerar a amplitude de profissões possíveis que compõem o mercado de trabalho, as ocupações dos imigrantes haitianos ficam restritas à apenas alguns setores que carecem de força de trabalho. Foram informadas, nas fichas da Cáritas Cascavel, algumas profissões exercidas pelos imigrantes haitianos em seu país de origem: Pedreiro, Repórter, Pintor, Secretária, Massagista, Soldador, Mestre de obras, Artista plástico, Pintor, Eletricista, Motorista, Costureira, Babá, Esteticista, Estudante, Metalúrgico, Professor de informática, Cabeleireiro, Mecânico.

É possível identificar que os migrantes trazem consigo uma série de aptidões e competências, contudo, os imigrantes haitianos não encontram, no mercado de trabalho em Cascavel, meios para desenvolver suas potencialidades. Reduz-se o trabalho dos imigrantes ao trabalho nos frigoríficos, construção civil, dentre outros. Com isso, obstáculos que normalmente impedem a entrada do imigrante no mercado de trabalho, podem tornar-se maiores, como, por exemplo, a questão da língua, escolaridade (e falta de instituições que validem o diploma em Cascavel), preconceito racial, dentre outras.

Buscando-se apurar com mais precisão as motivações da presença dos imigrantes haitianos em Cascavel, bem como suas dificuldades, aplicou-se questionários e entrevistas juntamente aos imigrantes haitianos e à representantes de órgãos públicos e instituições que trabalham na acolhida e inserção dos imigrantes na sociedade cascavelense. Assim, ao se pensar em traçar um perfil dos imigrantes haitianos em Cascavel, buscou-se levantar as seguintes informações: idade, sexo, profissão, bairro, dentre outras (Ressalta-se que em virtude das limitações de tamanho do presente ensaio, nem todas as informações citadas serão colocadas), para assim, possibilitar conhecer, de maneira geral, as características dos imigrantes que buscam atividades laborativas no município (as

2 Ressalta-se que os dados foram gentilmente cedidos pela Cáritas Arquidiocesana de Cascavel, a partir do atendimento aos imigrantes haitianos e seu posterior cadastro.

$\begin{array}{lllll}\text { Caminhos de Geografia } \quad \text { Uberlândia-MG } & \text { v. 21, n. } 78 \quad \text { Dez/2020 } & \text { p. 65-77 } & \text { Página } 71\end{array}$


informações foram retiradas de cadastros realizados pela Cáritas Cascavel nos anos de 2015, 2016 e até maio de 2017).

O gráfico 2 mostra a percentagem de imigrantes haitianos no município, por idade. Observa-se grande predominância de duas faixas etárias: $25-34$ anos (45\% do total) e $35-44$ anos (35\% do total). A faixa etária que compreende os imigrantes com 55-64 anos é a que apresenta menor percentagem de pessoas, $4 \%$ do total.

Gráfico 2 - Percentagem de imigrantes haitianos em Cascavel, por idade.

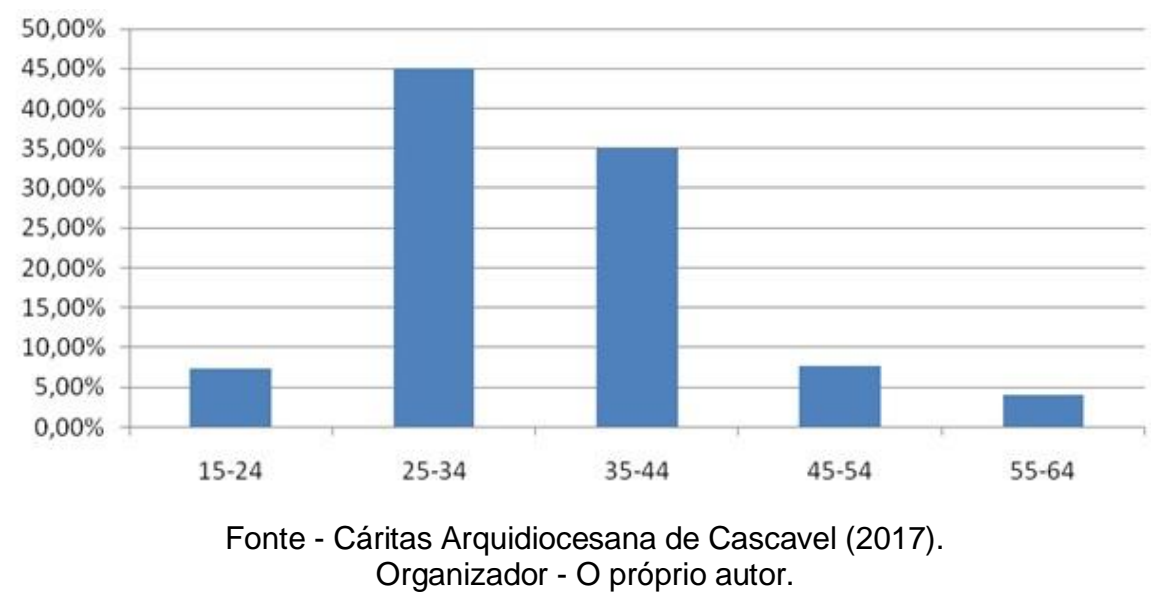

Outro ponto importante a ser ressaltado, a partir das informações do gráfico 2 é que a maioria dos imigrantes consultados se encontram em idade economicamente ativa, sendo força de trabalho ociosa e disponível. Em relação ao sexo, majoritariamente, os imigrantes haitianos em Cascavel são compostos por homens. Do total da amostra, 181 são homens e 73 são mulheres. Assim, cerca de $70 \%$ correspondem a homens e $30 \%$ a mulheres.

Levando-se em consideração as ocupações em que estão inseridos os imigrantes, o emprego disponível aos imigrantes assume características que tendem ao emprego da mão-de-obra masculina nas atividades. Observa-se que procuram o município de Cascavel, imigrantes em idade economicamente ativa, sendo a maioria do sexo masculino. A tendência é que, a partir desse perfil, os imigrantes sejam empregados nas atividades laborativas supracitadas.

No que refere-se às motivações que os levaram a deixar o Haiti, emergem várias proposições, apresentadas no gráfico 3. A principal proposição apresentada é "Trabalho", sendo $39 \%$ das respostas. Logo após, a opção "Melhores condições de vida" apresenta 17\% das respostas.

Gráfico 3 - O que o motivou a sair do Haiti?

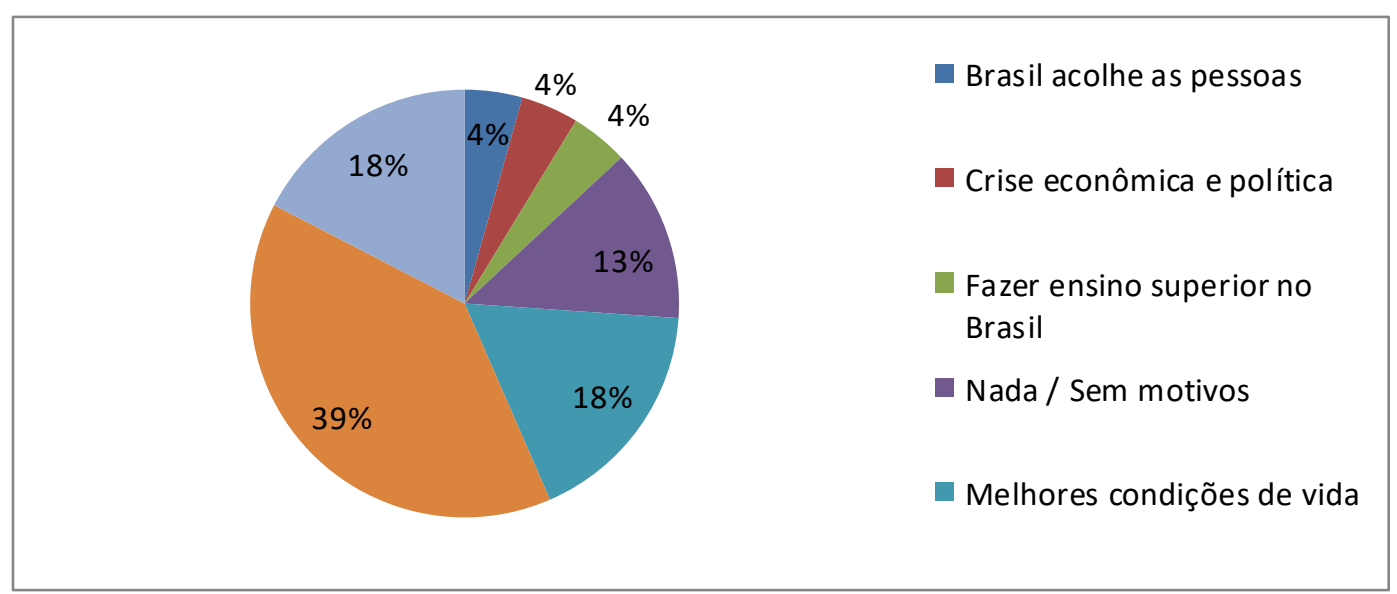

Fonte - Trabalho de campo (2017). 
Também, "Nada/Sem motivos", aparece com 13\% e as proposições "Fazer ensino superior no Brasil", "Crise econômica e política" e "Brasil acolhe as pessoas" aparecem com 4\% das respostas. As motivações relativas à saída da população haitiana, apresentadas, nos permitem observar como as características socioeconômicas do Haiti impulsionam a população à migração, evidenciadas a partir das respostas apresentadas.

Observa-se que houve, nas respostas, referências ao terremoto de 2010 (Ou até mesmo ao furacão Matthew), podendo-se inferir que alguns motivos apresentados têm relação com os fenômenos naturais que assolaram o país, ocasionando uma maior precarização das condições de vida da população haitiana, forçando-os a migrar. Fica evidenciada também a visão do Brasil como um país acolhedor, aberto à oportunidades e melhores condições de vida, a partir da resposta "Brasil acolhe as pessoas" (TRABALHO DE CAMPO, 2017). Pode-se inferir que essa resposta tenha relação com o contato da população haitiana com as tropas do exército brasileiro na Minustah.

Sobre a formação profissional dos imigrantes no Haiti e sua atual ocupação em Cascavel (gráfico 4), quando perguntados: "Essa atividade enquadra-se na sua formação profissional ou no que gostaria de atuar?", observa-se que $80 \%$ dos imigrantes responderam "não" e $20 \%$ responderam "sim".

Gráfico 4 - Essa atividade enquadra-se na sua formação profissional, ou no que gostaria de atuar?

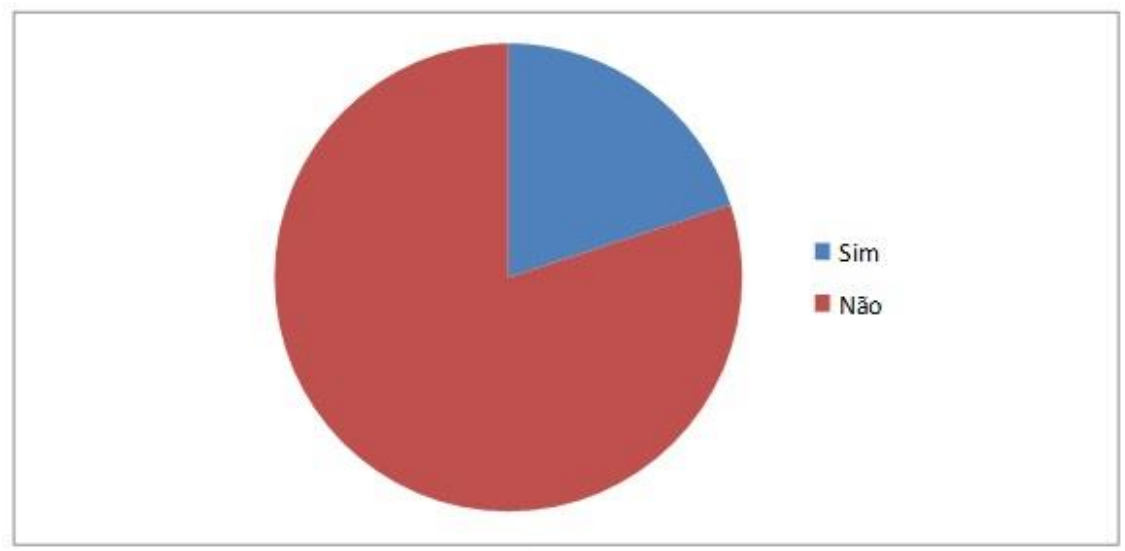

Fonte - Trabalho de campo (2017).

A não inclusão da maioria dos imigrantes haitianos no mercado de trabalho, em sua profissão original, é uma das questões que merecem destaque. Pode-se considerar que estejam atreladas ao: preconceito racial, xenobia e não-validação do diploma em território brasileiro, portanto, são fatores, dentre outros, que podem contribuir para essa questão.

Associado à esse fato, de como os imigrantes se inserem no mercado de trabalho, está a escolaridade. Teoricamente, quanto mais escolaridade apresentar determinado sujeito, maior as possibilidades de inserção no mercado de trabalho, contudo, percebe-se que o mesmo não ocorre com os imigrantes haitianos.

Salienta-se que para a transcrição e análise das entrevistas, os nomes utilizados pelos imigrantes haitianos são ficticios (mas comuns no Haiti) a fim de preservar a identidade dos entrevistados e valorizar a cultura haitiana com nomes típicos do país. Logo, buscando apreender as motivações pertinentes à migração dos haitianos para o Brasil, em diálogo com Patrick,

\section{O que o motivou a sair do Haiti? \\ Porque depois terremoto passar daí não tem serviço. \\ Daí vem pra cá [...] (Entrevista, 2017, grifo nosso).}

Observa-se que o trabalho surge como motivação pós-terremoto de 2010, embora o Haiti tenha um importante histórico de migração. É possível colocar o terremoto como sendo o grande marco da última diáspora haitiana, pois, a partir do fenômeno, as condições de vida no país tornam-se ainda mais precárias. A partir do terremoto, o motivo "trabalho" ganha força, estimulando a migração, como informado por Joel nos trechos a seguir:

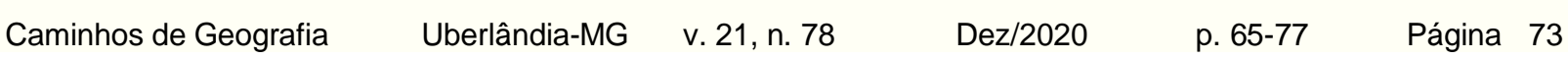


É o trabalho mesmo. Pra fora do Brasil, o que a mídia fala ... Que o Brasil, o Brasil primeiramente é o Rio de Janeiro e o Carnaval, o Brasil tem mulher bonita, que a mídia fala. O Brasil é o futebol.

Então ... Eu não sei jogar futebol, nunca ia vim pro Brasil depois do terremoto e ... Os haitianos vem pro Brasil e eu acho que as pessoas haitianas que tem mais tempo aqui deve ter [vindo] imediatamente depois do terremoto.

Acho que não tem um haitiano que tem dez anos aqui já, quase impossível.

Se é pra vim aqui pra sair do Haiti eu venho aqui especialmente para trabalhar e como eu gosto de estudar, eu acho uma oportunidade boa de estudar.

Mas pra vim aqui o objetivo é trabalhar (Entrevista, 2017, grifo nosso).

O depoimento mostra como é recente o fluxo migratório em direção ao Brasil. Fica claro que não é o Brasil o objetivo da migração haitiana. O objetivo é o trabalho, elucidado quando informado que "Se é pra vim aqui pra sair do Haiti eu venho aqui especialmente pra trabalhar". Vendo no Brasil possibilidade de inserção digna no mercado de trabalho, o país torna-se uma porta de entrada para o trabalho dos haitianos.

No que se refere aos problemas e dificuldades enfrentadas pelos imigrantes haitianos em Cascavel, a dificuldade em conseguir emprego, os problemas dentro das empresas, o preconceito racial e a precariedade das condições de moradia (e o valor do aluguel) emergem como problemas centrais. Nesse sentido, instituições ligadas à igreja trabalham na acolhida dos imigrantes em Cascavel. É o caso da Cáritas. Assim, foi realizada entrevista com a representante da entidade no município de Cascavel, na qual a mesma ressalta

A gente vai identificar a necessidade deles e a gente passa a trabalhar com eles. Só que nós não vamos trabalhar só com a documentação, a gente acaba se envolvendo pra além da documentação, porque a gente começa a perceber que eles precisam muito mais do que isso, entendeu, só de vir aqui e fazer a documentação e fazer esse encaminhamento (Entrevista, 2017).

Então, observa-se que a entidade trabalha no auxílio com a documentação dos imigrantes, como também em serviços de assistência social, por meio da articulação, juntamente ao setor público, de ações que visem a ascensão social dos imigrantes. Com a falta de mecanismos legais de validação de diplomas ou até mesmo o reconhecimento dos empregadores das aptidões dos haitianos, são relegados aos mesmos postos de trabalho que exigem pouca ou nenhuma qualificação profissional e salários baixos. Nesse contexto, ao se perguntar se exercem a mesma profissão do país de origem no Brasil, temos:

Por exemplo, ela tá querendo voltar trabalhar no lugar dela, ele também tá querendo voltar trabalhar, ele também tá querendo, ele também. Cada um tá querendo né, mas a oportunidade, não tem. Eles pensam que: - Ah, é haitiano, vem aqui no Brasil, que se ... ah, vai na Coopavel, vai na Globoaves.

Mas não é assim, cada um tem um profissão (Entrevista coletiva, 2017).

É elucidado como, mesmo para os haitianos, fica clara a visão de que os imigrantes têm necessariamente que se inserir no mercado de trabalho somente em determinadas atividades (braçais, que exigem pouca qualificação profissional e com baixos salários). Os haitianos vivem, então, num contexto de de difícil inserção no mercado de trabalho no município.

Quando perguntados sobre a satisfação com o trabalho no Brasil e sobre as dificuldades encontradas no município, empecilhos em relação à inserção no mercado de trabalho e problemas no cotidiano do trabalho foram elencados os seguintes:

Dificuldade só dentro da empresa. Algum encarregado que enche o saco. Tirando o serviço, vizinho é gente boa, qualquer gente é bem vindo né. Tirando o serviço ... (Entrevista coletiva, 2017, grifo nosso).

Depois chegou Cascavel salário muito, muito pouco. Depois entrar, assinar em carteira, novecentos (e) trinta pila.

Não, aqui não tem complicado. Só ... agora só trabalho que muito difícil um pouco agora (Robenson, Entrevista, 2017, grifo nosso). 
Posso falar de Cascavel e de Coopavel, porque eu conhece Cascavel e eu trabalhar na Coopavel, no momento que eu cheguei aqui, entendeu? Mas é, lá na Coopavel, no começo não sabia como que ia falar que Coopavel não era bom né, agora, depende como que é, eu posso falar pra mim que não é bom. É do tratamento lá, do jeito que eles tá tratando os povo lá, eu posso falar que não é bom, entendeu? É isso mesmo.

Só lá dentro do serviço. Só lá. Mas na rua, no bairro não, ainda não (risos) (Marcson, Entrevista, 2017, grifo nosso).

Observa-se, nos depoimentos anteriores, a importância do trabalho como elemento da realização ou não da inserção e/ou reprodução social do migrante. Por mais que o cotidiano, no ponto de vista do migrante, não seja conflituoso, sendo o trabalho dotado de problemas ou insatisfações, o migrante não se sente confortável ou estável.

No cotidiano do trabalho, percebe-se a partir do relato de Robert, a seguir, não aceitação da cultura do próximo, bem como o racismo sofrido e a pressão pela produtividade no ambiente de trabalho, nesse caso, na linha de produção da Coopavel.

Eu trabalhava lá na Coopavel, na sala de corte, evisceração, sangria, pendura ...

Aí tinha alguns problema lá que deu com um encarregado lá da sangria. Tava cantando música e coloca, tipo assim ... Sabe quando tá cantando uma música e cada parte da música colocar o nome da pessoa, só pra zoeira?

Ai nóis tava fazendo assim, de repente não sei que que deu com ele.

Ele falou: - Passou um frango!

Falei: - Ah, você tava lá atrás, porque você não cuida, to fazendo a minha parte veio.

Ai como ele fica bravo, deu o intervalo, depois do intervalo eu comecei cantar, todo mundo já tinha esquecido isso né.

E começou (comecei) canta ele chegou, me chamou de macaco. Ai falei:

- Quem que é o macaco?

Ele falou: - É você mesmo ...

Tipo assim, fi da ...

Ai peguei, sai. Melhor que eu sai dali pra não ficar misturado com ... junto com pessoa mal educada, entendeu? Ai eu deixei Coopavel pra ele (Robert, Entrevista, 2017, grifo nosso).

Assim, constatou-se que a permanência dos imigrantes haitianos em Cascavel depende das condições ou da disponibilidade de trabalho, como segue.

Só que depois eu sair lá (da Coopavel), se eu sai, se não consegue achar um serviço boa que eu quero, ai vai dar um vontade de sair da cidade, né? Pra ir em outra cidade pra procurar outro serviço (Marcson, Entrevista, 2017, grifo nosso).

Intervenção: Vocês pretendem ficar em Cascavel?

Sim, eu quero ficar. Se não tem trabalho aqui, eu não tenho empresa, eu vou lá no outro cidade, entendeu? Ou ... ou Santa Catarina (Entrevista coletiva, 2017, grifo nosso)

Ah, se eu colocar sim, eu tem que colocar seu eu conseguir serviço, sim. Caso contrário não (Willy, Entrevista, 2017, grifo nosso)

Sendo o "trabalho" o destino dos imigrantes, Cascavel pode, para alguns, ser o destino final de uma jornada em busca de melhores condições de vida, como para outros, pode ser mais um ponto da busca por uma inserção justa e digna no mercado de trabalho. O fato é que Cascavel, como bem coloca Martins et al (2014), converteu-se no elo de uma cadeia produtiva global, possibilitando-nos reiterar a máxima da não existência de fronteiras para a ação do capital. 


\section{CONSIDERAÇÕES FINAIS}

A migração haitiana em direção à Cascavel traz consigo um sentido principal: o trabalho. Sendo, antes de mais nada, força de trabalho e possuindo esta para sua sobrevivência, o migrante haitiano, à mercê das forças condicionantes do capital, busca em outro território o trabalho.

Logo, o limite da migração haitiana é também o limite imposto pelo capital no trabalho. Há que se ressaltar que o imigrante haitiano, que possui apenas sua força de trabalho quando migra, já está sujeito, desde então, à precarização do trabalho.

Ao se pensar na precarização do trabalho haitiana e num cenário de desemprego, pode-se traçar um perfil da imigração e do imigrante haitiano em Cascavel, territorialmente, bem como a partir de sua inserção no mercado de trabalho. Nesse sentido, conclui-se que: a) Territorialmente, o imigrante haitiano busca morar nas proximidades dos terminais, com a finalidade de facilitar sua locomoção; $b$ ) O motivo principal para a presença haitiana em Cascavel é a oferta de emprego nos frigoríficos e na construção civil; c) Os haitianos ficaram sabendo de Cascavel por meio das redes sociais de parentes e amigos, valendo ressaltar que foi a movimentação inicial do capital que condicionou a configuração dos caminhos percorridos e das redes sociais desses imigrantes no país; d) A validação de diplomas apresenta-se como grande questão e que dificulta uma inserção no mercado de trabalho em outras ocupações; e) O racismo e a xenofobia são problemas enfrentados pelos imigrantes em diferentes esferas do cotidiano e do trabalho; f) As condições sócio-estruturais, no caso, o aluguel, são dificuldades encontradas pelos imigrantes; g) Há ausência de políticas públicas efetivas para os imigrantes.

\section{REFERÊNCIAS}

BAPTISTE, Chandeline Jean; VIEIRA, Joice Melo. Catástrofe ambiental e migração internacional: a perspectiva dos migrantes haitianos na cidade de São Paulo. In: BAENINGER et al (Org.). Imigração haitiana no Brasil. Jundiaí: Paco editorial, 2016, p. 577-607.

CADASTRO GERAL DE EMPREGados E DESEMPREGADOS. Perfil do Município. Disponível em: < http://bi.mte.gov.br/bgcaged/caged perfil municipio/index.php > Acesso em: 19 de Outubro de 2017.

CÁRITAS BRASILEIRA. Quem somos e histórico. Disponível em: <http://caritas.org.br/quemsomos-e-historico> Acesso em: 19 de Outubro de 2017.

DANTAS, Mariana. Grupo de 44 haitianos busca melhorar de vida em Cascavel. Jornal Hoje, Cascavel/PR, p. 6, 31/01/2012.

FERNADES, D; FARIA, A. V. A diáspora haitiana no Brasil: processo de entrada, características e perfil.In: BAENINGER et al (Org.). Imigração haitiana no Brasil. Jundiaí, Paco editorial, 2016, p. 95111.

GAUDEMAR, Jean-Paul de. Mobilidade do trabalho e acumulação do capital. Lisboa; estampa, 1977.

MARTINS, José Renato Vieira (et al.) A diáspora haitiana: Da utopia à realidade. Foz do Iguaçu: Gráfica Grapel, 2014.

NUNES, Lineker Alan Gabriel Nunes. Migração e trabalho: O caso dos haitianos em Cascavel/PR. 2017. Dissertação (Mestrado em Geografia) - Universidade Estadual de Londrina, Centro de Ciências Exatas, Programa de Pós-Graduação em Geografia, 2018.

MARX, Karl. O capital. Crítica da economia política. Vol I, São Paulo: Nova Cultural, 1996.

SAYAD, Abdelmalek. Imigração ou os paradoxos da alteridade. São Paulo: Edusp, 1998, 299 p.

SISTEMA NACIONAL DE CADASTRAMENTO DE REGISTRO DE ESTRANGEIROS - SINCRE. SINCRE. Disponível em: <http://obmigra.mte.gov.br/index.php/component/k2/itemlist/category/51> Acesso em: 20 de Junho de 2017.

THOMAZ JUNIOR, Antonio. Por uma Geografia do Trabalho (reflexões preliminares). 2002. Disponível em: <http://www2.fct.unesp.br/thomaz/Geografia\%20do\%20Trabalho-2016/ltrodu\%E7\%E3o/Texto-Pos-1Thomaz-Por\%20uma\%20Geografia\%20do\%20Trabalho.pdf> Acesso em 06 de maio de 2017.

$\begin{array}{llllll}\text { Caminhos de Geografia } & \text { Uberlândia-MG } & \text { v. 21, n. } 78 & \text { Dez/2020 } & \text { p.65-77 } & \text { Página } 76\end{array}$


VILLEN, Patrícia. O estigma da ameaça ao emprego pelos periféricos na periferia: Crise e imigração no Brasil. Revista Rua, Campinas, Número 21 - Volume 2, Novembro/2015, p. 247 - 264. Disponível em: <https://periodicos.sbu.unicamp.br/ojs/index.php/rua/article/view/8642466>. Acesso em: 21 de Julho de 2019. https://doi.org/10.20396/rua.v21i2.8642466

Recebido em: 03/03/2020

Aceito para publicação em: 21/06/2020 